\section{Sette piani}

\author{
E. Taverna
}

In der berühmten Erzählung der «Sieben Stockwerke» beschreibt Dino Buzzati ein modernes Spital. Wir lernen es aus der Sicht eines Patienten kennen, der mit jeder Verlegung auf die nächste, tiefere Etage seinem unaufhaltsamen Ende entgegengeht. Alle sind nett zu ihm, optimistisch und guter Laune. Eine gut geölte Maschine versorgt ihn klinisch effizient nach einer ausgeklügelten, wenn für ihn auch undurchschaubaren Routine. Auf dem langsamen Weg in die Tiefe wächst das Grauen. Die Ärzte und Schwestern erklären und beschwichtigen, sie haben für jede angstvolle Frage umgehend eine rationale, absolut logische und plausible Antwort. Der Patient stirbt in Raten, ausgeliefert und hilflos, während sein Bett wieder einmal abwärts verschoben wird.

Wir sind es gewohnt, dass die endlosen Spitalserien aller Fernsehketten die heile Welt der blitzblanken Operationssäle, dynamischen Notfallärzte und sauberen Betten feiern. Ob fiktiv oder nicht, sie trösten und beruhigen, sie zeigen eine Insel im Chaos, bewohnt von kompetenten Menschen, die Gutes tun.

Die überzeichnete Gegenwelt finsterer Komplotte, korrupter Ärzte und grausiger Experimente gehört dem Horrorfilm, dem Thriller oder der Science-fiction. Darin geht es meistens um Organhandel und Transplantationen oder um Menschenversuche in der Grauzone neuer Reanimationstechniken. Die Filme bieten ausser Unterhaltung auch eine Art von mentalem Labor für kollektive Ängste, die durchaus berechtigt sind. Sie mögen einseitig und pessimistisch sein, aber sie sind nicht weniger real als die erwähnten Serien, die zur kinderfreundlichen Stunde über den Bildschirm flimmern. Sie widerspiegeln auch etwas, das praktisch immer ausgespart bleibt: die real existierenden Gefängnis- und Kriegsspitäler, die unterversorgten und überbelegten Slumkliniken oder das krasse Gegenteil, die abgeschirmten, nur den Reichsten und Mächtigsten vorbehaltenen Häuser.

Was Buzzati in "Sette piani" entwickelt, hat der dänische Regisseur Lars von Trier in Form einer Seifenoper für das Fernsehen gedreht. Die Serie «Hospital der Geister" entstand 1994 und 1997 und wurde $\mathrm{zu}$ einem internationalen Kino- und Kritikererfolg. Die ironisch-schauerliche Serie im Milieu eines grossen Krankenhauses hat inzwischen Kultstatus erreicht und war kürzlich sogar in unserem biederen SF-1-
Programm zu sehen, wenn auch zensurgerecht jeweils unter der Woche um 23.55 Uhr. Der 1956 geborene Lars von Trier gehört zu einer Generation überaus aktiver dänischer Filmer, die hierzulande wenig bekannt sind, weil sie, wie die anderen Europäer, im amerikanisch dominierten Verleihgeschäft weniger Chancen haben. Dabei ist er einer der wichtigsten und interessantesten Autorenfilmer und vielfacher Festivalpreisträger. Er hat seinen unverwechselbaren Stil entwickelt, mit einer Vorliebe für Träume und Alpträume, die an künstlerische Vorbilder wie Andrej Tarkowskij und Carl Theodor Dreyer erinnern. Auch in unseren Kinos gespielt und bekannt ist das Melodrama "Breaking the Waves" von 1996 und sein radikaler Spielfilm «Die Idioten» von 1998.

Im metaphysischen Grusel vom "Königlichen Reichsspital", erbaut auf einem ehemaligen Sumpfgelände, "wo die Färber ihre Geschichten erzählten», überwuchert die Innenwelt von Buzzatis Patient die ganze Klinik. In drei Folgen entfaltet sich die alptraumhafte Geschichte eines vertuschten Kindermordes, der eine Kette weiterer Machtkämpfe, mit Intrigen und weiteren Opfern auslöst. Die verschiedenen Handlungen sind die Ursache übernatürlicher Phänomene, die nur von einer umherirrenden, angeblich senilen, Dauerpatientin und einem geistig behinderten Tellerwäscher, der am Fliessband der Spitalküche arbeitet, wahrgenommen werden. Geister und Spuksymptome beherrschen die langen Kliniknächte notbeleuchteter Gänge, dunkler Treppenhäuser und labyrinthartiger Kellergeschosse. Szenen absurder Arztrapporte und seltsamer Aufzeichnungen modernster Diagnostikgeräte wechseln mit Einbrüchen im gesicherten Klinikarchiv, "dem Ort des Schmerzens", wo die sich die Wege aller Gegenspieler ungewollt kreuzen. Obskure Logentreffen der ärztlichen Ethik- und Rechtskommission unter den gewundenen Rohren entlegener Keller und ein Pathologieprofessor, dessen Gewebesammlung nicht über alle Zweifel erhaben ist, erinnern an sehr reale Vorbilder. Lars von Trier verzichtet auf Slapstickmethoden oder Schockelemente. Wachtraum und Realität vermischen sich. Wer Nachtwachen kennt, übermüdete Morgenstunden, einsame Flure und hallende Betongänge im dunklen Gedärme der mehrstöckigen Unterwelt eines Spitalkomplexes, braucht wenig Phantasie, um in das spukhafte, halluzinogene Schattenreich abzutauchen. Lars von Triers Groteske des absurden Leerlaufs, der doppelbödigen Spitalmaschine, des verborgenen Wahnsinns und des bedrohlichen Selbstzwecks ist ein notwendiges Gegengift zur Überdosis der sterilen Ordnung endloser Arztserien. 